\title{
Abutilon indicum L (Malvaceae)-Medicinal Potential Review
}

\author{
Rajagopal Ramasubramania raja ${ }^{* 1}$ and Koumara Velou Kailasam² \\ 'Department of Pharmacy, Research Scholar PRIST University, Thanjavur, T.N, India. \\ ${ }^{2}$ Registrar, PRIST University, Thanjavur, T.N, India.
}

\begin{abstract}
The plant Abutilon Indicum (Linn.) is belonging to malvaceae family; Also known as Mallow in english, Abutilon indicum is used as a medicinal plant. It has been reported that Abutilon indicum has Anti inflammatory and Antiproliferative activity, Anti-Arthritic activity, Analgesic and Sedative property, Antioxidant and Antimicrobial activity, Hepatoprotective activity, Anti diabetic, Anti cancer, Anti diarrhoeal, Anti-convulsant, Larvicidal, Wound healing, Anti asthmatic, Diuretic, Immunomodulatory, and Anti-estrogenic activity. It is proved that this plant contains carbohydrates, proteins and aminio acids, saponins, flavanoids, glycosides, phytosterols and phenolic compounds.
\end{abstract}

Key words: Abutilon indicum, Anti-proliferative activity, Anti asthmatic, Hepatoprotective activity, Phenolic compounds.

\section{SUMMARY}

- Abutilon indicum (Linn) of family Malvaceae is a medicinal shrub, It is commonly called as Thuthi/Atibala, is distributed throughout the India and used in our traditional system of medicine for various diseases.

- Plants contain several chemical constituents such as phenolics, terpenoids, flavanoids, pigments and other natural oxidants including Vitamin A, Vitamin $\mathrm{C}$ and Vitamin $\mathrm{E}$ that have been associated with protection from treatment of chronic diseases like heart diseases, cancer, diabetes and hypertension as well as other medicinal conditions.

- It has been proved various pharmacological activity some examples are Analgesic and Sedative property, Antioxidant and Antimicrobial activity, Hepatoprotective activity, Anti diabetic, Anti cancer and etc.

\section{PICTORIAL ABSTRACT}

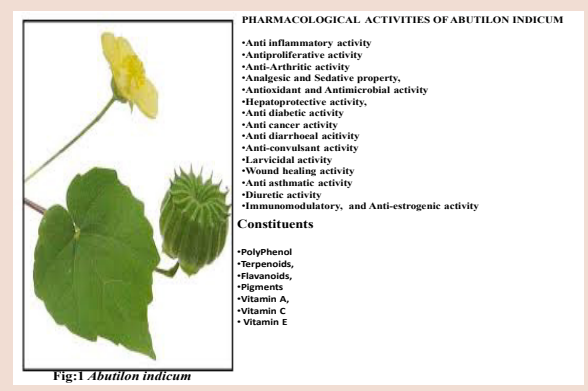

Abbreviations used: $I C_{50}$ : Half maximal inhibitory concentration, (5-LOX): 5-Lipoxygenase, CASP9: Caspase 9, Apoptosis-Related Cysteine Peptidase CASP3: Cysteine-aspartic acid protease, CYCS: Cytochrome C, Somatic GABA: Gamma-aminobutyric acid, TP53: Tumor Protein P53, HSPA4: Heat shock $70 \mathrm{kDa}$ protein 4.

Correspondence:

Mr. Rajagopal Ramasubramania raja, Department of Pharmacy, Research Scholar, PRIST University, Thanjavur, T.N, India.

Phone no: 09494516207

Email: rsmr_raj@yahoo.co.in DOI : $10.5530 /$ pj.2015.6.2

\section{INTRODUCTION}

Synonyms: Rishyaprokta, Kankatika, Balika, Rishagadha, Bhuribala. Vernacular names:

Tamil :

Bengali :

Marathi:

Gujarati:

Malayalam:

Arabian:

English:

Hindi:

Kannada:

Telugu:

Farsi:

\author{
Perum Tutti, Paniyara Hutti, thuthi \\ Petari, Jhapi \\ Mudra \\ Khapat, Dabali, Kamsaki \\ Vellula \\ Masthul Gola \\ Country mallow \\ Kanghi, Kakahi \\ Tutti \\ Tutturu Benda, Duvvenakaya, Duvvena \\ Kayalu \\ Darakhtashaan
}

Common Name: Abutilon, Indian mallow.

Habitat: Present in sub-Himalayan tract and hills up to $1,200 \mathrm{~m}$ and hotter parts of India.

Traditional applications: It is useful in gout, tuberculosis, ulcers, bleeding disorders, and worms. It can be used as Digestive, laxative, expectorant, diuretic, astringent, analgesic, anti inflammatory, anthelmintic, demulcent and aphrodisiac. Decoction used in toothache and tender gums. Demulcents of leaves are locally applied to boils and ulcers. Roots are prescribed in fever, chest affection and urethrities.
Abutilon indicum (Linn.) Figure 1 is three meter in height. Traditionally, Root and bark are used as aphrodisiac, anti diabetic, nervine tonic, and diuretic. Seeds are used in urinary disorders. The seeds are used as a laxative in piles and in the treatment of cough. The Phyto chemical investigation of $A$. indicum leaves showed the presence of amino acids, glucose, fructose and galactose. From the roots, non-drying oil consisting of various fatty acids viz. linoleic, oleic, stearic, palmitic, lauric, myristic, caprylic, capric and unusual fatty acid having $\mathrm{C}_{17}$ carbon skeleton, sitosterol, and amyrin from unsaponifiable matter were yielded.

\section{Phyto-Pharmacological evidence of Abutilon indicum (L.)}

\section{Anti inflammatory and Anti proliferative Activity}

The Anti inflammatory and Anti proliferative activity of ethanolic leaf extract of Abutilon indicum for potential chemo preventive agent has been evaluated by kaladhar et al. The ethanolic leaf extract of $A$. indicum is revealed good anti inflammatory activity $\left(\mathrm{IC}_{50}: 8.89 \mu \mathrm{g} / \mathrm{mL}\right.$ ) based on $5-\mathrm{Li}$ poxygenase (5-LOX) inhibition assay. It has also shown good response on human Caucasian lung carcinoma of A549 cell line $\left(\mathrm{IC}_{50}: 85.2 \mu \mathrm{g} / \mathrm{mL}\right)$ shows anti proliferative activity. Bioactive components present in the ethanolic leaf extract of $A$. indicum shows good anti inflammatory and anti proliferative activity by inducing Apaf-1 through CASP9, CASP3, CYCS, BCL2L1, TP53, BCL2, CASP8, HSPA4, DIABLO and CASP7 network. ${ }^{1}$ 


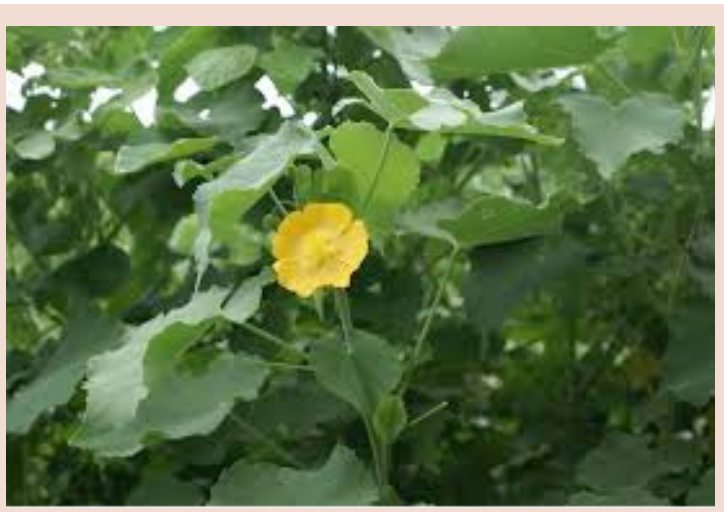

Figure 1: Abutilon indicum Linn

\section{Anti Arthritic Activity}

Nitin S. Bhajipale et al screened the various extracts of Abutilon indicum (AI) and investigated for its anti arthritic activity in In vitro studies in male albino rats. The methanolic extract of Abutilon indicum exhibited significant anti-arthritic activity. Treatment with Abutilon indicum 400 $\mathrm{mg} / \mathrm{kg}$ had showed significant reduction $(\mathrm{P}<0.01)$ in paw volume on both $7^{\text {th }}$ and $14^{\text {th }}$ day. ${ }^{2}$

\section{Analgesic and Sedative property}

Deepraj Paul et al evaluated the hydro alcoholic extract of aerial parts of Abutilon Indicum tried for its efficacy as analgesic and sedative property. As the extract has shown very significant $(\mathrm{P}<0.01)$ result in Eddy's hot plate, acetic acid induced writhing test and hot water immersion test. The extract has certain central and peripheral analgesic property. The extract may have GABA mimetic or facilitating effect. Author reported that in future it will gain more popularity to be used as a substitute for narcotics to treat pain and also as a good sedative. ${ }^{3}$

\section{Antioxidant and Antimicrobial activity}

Dhirender Kaushik et al designed to evaluate the antioxidant and antimicrobial activities of chloroform fraction of alcoholic extract of whole plant of Abutilon indicum extract was screened for antioxidant and free radical scavenging effects at various concentrations. The antimicrobial activity was studied using the agar well diffusion assay. Extract of Abutilon indicum was found to be most effective against Staphylococcus aureus followed by Bacillus sublitis whereas in case of Gram negative bacteria, extract was found to be most effective against Escherichia coli showing the maximum zone of inhibition followed by Pseudomonas aeruginosa. The ethanolic extract showed high activity against $C$. albicans than that of standard drug amphotericin B. ${ }^{4}$

\section{Hepatoprotective activity}

Rohit Gupta et al evaluate the hepatoprotective activity of hydroalcoholic and ethyl acetate extract of leaf of Abutilon indicum (AI) in $\mathrm{CCl}_{4}$ induced toxicity in Sprague dawley rats. The hydroalcoholic extract at the dose of $200 \mathrm{mg} / \mathrm{kg}$ and $400 \mathrm{mg} / \mathrm{kg} \mathrm{b}$. wt and ethyl acetate extract $200 \mathrm{mg} / \mathrm{kg}$ b. wt was evaluated by inducing hepatotoxicity with $\mathrm{CCl}_{4}$ and using silymarin $(100 \mathrm{mg} / \mathrm{kg})$ as the reference standard. Biochemical parameters like, AST, ALT, ALP, total protein, triglyceride and serum bilirubin level was analysed. A section of liver was subjected to histopathological studies. It is reported that the ethyl acetate extract of Abutilon indicum possess greater hepatoprotection as compared to hydroalcohlic extract against $\mathrm{CCl}_{4}$ induced hepatotoxicity in albino rats. ${ }^{5}$

\section{Anti diabetic Activity}

Chutwadee Krisanapun et al evaluated A. indicum L. improves insulin sensitivity. First, we observed the antidiabetic activity of aqueous extract of the entire plant (leaves, twigs and roots) of A. indicum L. on postprandial plasma glucose in diabetic rats. The crude extract could activate glucose transporter 1 (GLUT1) promoter activity. These results suggest that the extract from $A$. indicum L. may be beneficial for reducing insulin resistance through its potency in regulating adipocyte differentiation through PPAR $\gamma$ agonist activity, and increasing glucose utilization via GLUT1 $^{6}$

\section{Anticancer activity}

Srikanth $\mathrm{P}$ et al study medicinal plants namely Abutilon indicum and Blumea mollis were chosen to screen for potential anti-oxidant properties and cytotoxic activity. The extract was also screened to assess the antioxidant activity using FRAP, 1, 1-Diphenyl-2-picrylhydryzyl [DPPH] radical scavenging activity and Nitric Oxide radical inhibition estimated by the use of Griess Illosvoy reaction with slight modification. These extracts show anti-oxidant properties as well as inhibitory effect on cancer cells with the increased concentration and duration. ${ }^{7}$

\section{Anti diarrhoeal activity}

Leaf extracts of Abutilon indicum were evaluated for anti-diarrhoeal activity by gastro-intestinal motility, castor oil-induced diarrhoea. The methanolic and aqueous extracts showed significant anti diarrhoeal activity in castor oil-induced diarrhoea and prostaglandin E2- induced diarrhoea. These extracts reduced diarrhoea by inhibiting intestinal peristalsis; gastrointestinal motility and PGE2 induced enteropooling. ${ }^{8}$

\section{Anti convulsant activity}

Anticonvulsant activity of Abutilon indicum leaf extracts was investigated by Golwala et al. The ethanolic extract was found to increase the onset of clonic convulsions and decreased onset of tonic seizures and thus exhibited a significant anti-convulsant effect. The aqueous extracts showed significant protective effect by increasing the onset of clonic convulsion time and decreasing extensor time as compared to control group. This anticonvulsant effect was attributed to linoleic acid and/or flavonoid constituents present in the extracts. ${ }^{9}$

\section{Larvicidal activity}

Larvicidal activity of crude hexane, ethyl acetate, petroleum ether, acetone and methanolic extracts of Abutilon indicum were assayed for their toxicity. All extracts showed moderate larvicidal effects. But highest larval mortality was found in petroleum ether extract. Furthermore, ${ }^{1} \mathrm{H}$ $\mathrm{NMR},{ }^{13} \mathrm{C}$ NMR and mass spectral data confirmed the identification of $\beta$-sitosterol as a potential new mosquito larvicidal compound with $\mathrm{LC}_{50}$ value of 26.67 ppm against C. Quinquefasciatus. ${ }^{10}$

\section{Wound healing activity}

P Ganga suresh et al evaluated the wound healing activity of Abutilon indicum Linn. There was a significant increase in wound closure rate. All the extracts were obtained subjected to phytochemical studies. The progressive changes in the wound area were monitored by tracing the wound margin every day. From the result, it is concluded that the petroleum ether extract of "Abutilon indicum" Linn had greater wound healing activity than the Ethanolic extract. ${ }^{11}$

\section{Anti asthmatic activity}

This study reported the effectiveness of powder of dried aerial parts of Abutilon indicum in decreasing the severity of commonly observed 
symptoms of bronchial asthma i.e. dyspnoea, cough, chest tightness and wheezing. It was also found to significantly increase the pulmonary function measured as forced vital capacity (FVC), forced expiratory volume in $1 \mathrm{Sec}$ (FEV1) and peak expiratory flow rate (PEFR) in patients having mild to moderate bronchial asthma. ${ }^{12}$

\section{Diuretic activity}

Seed extract of Abutilon indicum (200 and $400 \mathrm{mg} / \mathrm{kg}$ ) were evaluated for its diuretic effect. The extract at doses of 200 and $400 \mathrm{mg} / \mathrm{kg}$ produced significant dose dependant increase in urinary excretion and urinary sodium loss but no effect on intrinsic potassium sparing effect. ${ }^{13}$

\section{Immunomodulatory activity}

Dashputre et al. studied the immunomodulatory activity of ethanolic and aqueous extract of leaves of Abutilon indicum $(200 \mathrm{mg} / \mathrm{kg}$ and 400 $\mathrm{mg} / \mathrm{kg}$ ) by heamagglutination antibody (HA) titre, delayed type hypersensitivity (DTH), neutrophil adhesion test and carbon clearance test. It also showed significantly potentiated DTH reaction and increase in percentage neutophil adhesion test. The results of the study reported that both the extracts were found to have a significant immunostimulatory activity. ${ }^{14}$

\section{Anti estrogenic activity}

Johri et al. studied the anti-estrogenic effect of methanolic extracts of Abutilon indicum on uterotropic and uterine peroxidase activities in ovariectomized rats. This extract was found to cause significant suppression of enzyme activity as well as uterotropic response induced by estradiol, whereas in the group, not treated with estradiol, a marginal stimulation in peroxidase activity was observed. ${ }^{15}$

\section{In vitro anti arthritic activity}

Water soluble extract of Abutilon indicum (linn.) was studied by testing three in vitro parameters: protein denaturation, membrane stabilisation and protease inhibition. Abutilon indicum at doses (100 and $250 \mathrm{mcg} /$ $\mathrm{ml}$ ) provided significant protection against denaturation of proteins and hypotonic saline induced RBC membrane damage. It also exhibited significant anti-protease activity. ${ }^{16}$

\section{CONCLUSION}

Abutilon indicum have many more pharmacological properties like, hepatoprotective, wound healing, immunomodulatory, analgesic, antimalarial, antimicrobial, hypoglycemic activity. The main chemical constituents are carbohydrates, steroids, glycosides, flavonoids, tannins and Phenolic compounds. Hence this review article, effort has been taken to collect and compile the details notes on Abutilon indicum which will be useful to the society to venture into a field of alternative systems of medicine.

\section{ACKNOWLEDGEMENTS}

I express my sincere thanks to co-author, Director of research and Vice chancellor, subjects involved in study and persons who where directly or indirectly helped me in to carry out my work. I acknowledge the source of inspiration and moral support given to me by my family members.

\section{CONFLICTS OF INTEREST}

Authors do not have any conflict of interest.

\section{REFERENCES}

1. Kaladhar DSVGK, Swathi Saranya K, Varahalarao Vadlapudi, Nagendra Sastry Yarla. Evaluation of Anti-inflammatory and Anti-proliferative Activity of Abutilon indicum L. Plant Ethanolic Leaf Extract on Lung Cancer Cell Line A549 for System Network Studies. Cancer Science and Therapy 2014; 6(6): 188-94.

2. Nitin Bhajipale S. Evaluation of Anti-Arthritic Activity of Methanolic Extract of Abutilon Indicum. International Journal of ayurvedic and herbal medicine 2012; 2(3): 598-603

3. Deepraj paul, Karthika paul, Anuradha TS. Evaluation of hydroalcoholic extract of aerial parts of Abutilon indicum for its analgesic and sedative property Deepra Paul et al. Int. Res. J. Pharm. 2013; 4(5): 216-8.

4. Dhirender Kaushik, Sukhbir Khokra L, Pawan Kaushik, Chetan Sharma, Aneja KR. Evaluation of antioxidant and antimicrobial activity of Abutilon indicum. Pharmacology online 2010 1(1): 102-8.

5. Rohit Gupta, Swati Patil, Divya Shetty. Hepatoprotective Activity of Hydroalcoholic and Ethyl Acetate Extract of Abutilon Indicum Leaf on Rats. Int. J. Pharm. Sci. Rev. Res. 2015; 31(1): 68-71.

6. Chutwadee Krisanapun, Seong-Ho Lee, Penchom Peungvicha, Rungravi Temsiririrkkul, Seung Joon Baek. Antidiabetic Activities of Abutilon indicum (L.) Sweet Are Mediated by Enhancement of Adipocyte Differentiation and Activation of the GLUT1 Promoter. Evidence-Based Complementary and Alternative Medicine 2011; 2011: Article ID 167684, 9

7. Chandrashekhar VM, Nagappa AN, Channesh TS, Habbu PV, Rao KP. Antidiarrhoeal activity of Abutilon indicum Linn leaf extract. J Natural Remedies 2004; 1(4): $12-6$.

8. Golwala DK, Patel LD, Vaidya SK, Bothara SB, Mani M, Patel P. Anticonvulsant activity of Abutilon indicum leaf. Int J Pharmacy Pharm Sci. 2010; 2(1): 66-71.

9. Abdul Rahuman A, Gopalakrishnan G, Venkatesan P, Geetha K. Isolation and identification of mosquito larvicidal compound from Abutilon indicum (Linn.) Sweet. Parasitol Res. 2008 Apr; 102(5): 981-8.

10. Ganga suresh P, Ganesana R, Dharmalingam M, Baskar S, Senthil kumar P. Evaluation of Wound Healing Activity of Sbutilon indicum Linn, In Wister Albino Rats. International Journal of Biological and Medical Research 2011; 2(4): 908-11.

11. Paranjape AN, Mehta AA. Investigation into the Mechanism of Action of Abutilon indicum in the Treatment of Bronchial Asthma. Global J Pharmacol. 2008; 2(2): 23-30

12. Balamurugan G, Selvarajan S, Dhanapal B, Muralidharan P. Herbal anticonvulsants. J Herbal Med Toxicol. 2010; 4(1): 49-52.

13. Dashputre NL, Naikwade NS. Immunomodulatory activity of Abutilon indicum linn on albino mice. Int J Pharma Sci Res. 2010; 1(3): 178-84.

14. Johri RK, Pahwa GS, Sharma SC, Zutshi U. Prolonged intrauterine contraception: a seven-year randomized study of the levonorgestrel $20 \mathrm{mcg} / \mathrm{day}(\mathrm{LNg} 20)$ and the Copper T380 Ag IUDS. Contraception 1991; 44(5): 549-57.

15. Deshpande V, Jadhav VM, Kadam VJ. Psoralea corylifolia Linn.-Kushtanashini. J Pharma Res. 2009; 2(4): 644-5.

16. Vallabh Deshpande, Jadhav VM, Kadam VJ. In vitro anti-arthritic activity of Abutilon indicum (Linn.) sweet. Journal of Pharmacy Research 2009; 2(4): 644-5.

\section{ABOUT AUTHORS}

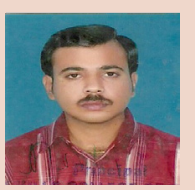

Mr. Rajagopal Ramasubramania raja: Has completed M.Pharm (Phytomedicine and Phytopharmacy) at SASTRA University, Tamilnadu. $\mathrm{He}$ is Pursuing PhD at part time in PRIST Univeristy, Tamilnadu. He is the Asst. Professor of Narayana Pharmacy College, Nellore Andhra Pradesh. 